\title{
Incorporation of advanced aerosol activation treatments into CESM/CAM5: model evaluation and impacts on aerosol indirect effects
}

\author{
B. Gantt ${ }^{1, *}$, J. He ${ }^{1}$, X. Zhang ${ }^{1}$, Y. Zhang ${ }^{1}$, and A. Nenes ${ }^{2,3}$ \\ ${ }^{1}$ Department of Marine, Earth, and Atmospheric Sciences, North Carolina State University, Raleigh, NC, USA \\ ${ }^{2}$ School of Earth and Atmospheric Sciences, Georgia Institute of Technology, Atlanta, GA, USA \\ ${ }^{3}$ School of Chemical and Biomolecular Engineering, Georgia Institute of Technology, Atlanta, GA, USA \\ * now at the Atmospheric Modeling and Analysis Division, National Exposure Research Laboratory, US Environmental \\ Protection Agency, Research Triangle Park, North Carolina, USA
}

Correspondence to: Y. Zhang (yang_zhang@ ncsu.edu)

Received: 15 October 2013 - Published in Atmos. Chem. Phys. Discuss.: 10 December 2013

Revised: 5 June 2014 - Accepted: 16 June 2014 - Published: 24 July 2014

\begin{abstract}
One of the greatest sources of uncertainty in the science of anthropogenic climate change is from aerosolcloud interactions. The activation of aerosols into cloud droplets is a direct microphysical linkage between aerosols and clouds; parameterizations of this process link aerosol with cloud condensation nuclei $(\mathrm{CCN})$ and the resulting indirect effects. Small differences between parameterizations can have a large impact on the spatiotemporal distributions of activated aerosols and the resulting cloud properties. In this work, we incorporate a series of aerosol activation schemes into the Community Atmosphere Model version 5.1.1 within the Community Earth System Model version 1.0.5 (CESM/CAM5) which include factors such as insoluble aerosol adsorption and giant cloud condensation nuclei $(\mathrm{CCN})$ activation kinetics to understand their individual impacts on global-scale cloud droplet number concentration (CDNC). Compared to the existing activation scheme in CESM/CAM5, this series of activation schemes increase the computation time by $\sim 10 \%$ but leads to predicted CDNC in better agreement with satellite-derived/in situ values in many regions with high CDNC but in worse agreement for some regions with low CDNC. Large percentage changes in predicted CDNC occur over desert and oceanic regions, owing to the enhanced activation of dust from insoluble aerosol adsorption and reduced activation of sea spray aerosol after accounting for giant $\mathrm{CCN}$ activation kinetics. Comparison of CESM/CAM5 predictions against satellite-derived cloud optical thickness and liquid water path shows that the up-
\end{abstract}

dated activation schemes generally improve the low biases. Globally, the incorporation of all updated schemes leads to an average increase in column CDNC of $150 \%$ and an increase (more negative) in shortwave cloud forcing of $12 \%$. With the improvement of model-predicted CDNCs and better agreement with most satellite-derived cloud properties in many regions, the inclusion of these aerosol activation processes should result in better predictions of radiative forcing from aerosol-cloud interactions.

\section{Introduction}

The interaction between cloud and aerosols is among the most uncertain aspects of anthropogenic climate change (Boucher et al., 2013). By serving as cloud condensation nuclei (CCN), anthropogenic aerosols can increase droplet number concentration and enhance the albedo of liquidphase clouds (Twomey, 1974, 1977). In reducing droplet size, anthropogenic $\mathrm{CCN}$ can inhibit drizzle production under certain conditions and lead to increased liquid water content, cloud lifetime, and cloud albedo (Albrecht, 1989). These two processes are referred to as the radiative forcing from aerosol-cloud interactions and adjustments and collectively constitute the effective radiative forcing from aerosol-cloud interactions in the Fifth Assessment Report from the Intergovernmental Panel on Climate Change (Boucher et al., 2013). An important aspect of aerosol-cloud interactions 
involves the process of aerosol activation into droplets (also referred to as droplet nucleation), which describes the growth of aerosols into cloud droplets. Although Köhler theory (Köhler, 1936) accurately predicts the activation of particles at a given maximum supersaturation, it is the determination of the maximum supersaturation that is the greatest source of uncertainty (Ghan et al., 2011). The earliest representations of droplet nucleation in climate models used empirical relationships between cloud droplet number concentration (CDNC) and sulfate mass concentration (Boucher and Lohmann, 1995) or aerosol number concentration (Jones et al., 1994). Despite relatively strong relationships between CDNC and these aerosol parameters in several environments (Leaitch et al., 1992; Martin et al., 1994; Ramanathan et al., 2001), the empirical relationships do not explicitly account for the dependence of the droplet nucleation on aerosol size distribution, aerosol composition, or updraft velocity and therefore are limited in their ability to accurately predict CDNC on a global scale.

Physically based parameterizations of aerosol activation or droplet nucleation are designed to quickly provide the number of aerosols activated into cloud droplets as a function of the aerosol number size distribution, chemical composition, and environmental conditions. One of the most widely used parameterizations describing aerosol activation, AbdulRazzak and Ghan (2000) (hereto referred as AR-G00), is based on the work of Abdul-Razzak et al. (1998) and derives a semi-empirical treatment of supersaturation by adjusting coefficients on physically based terms to achieve agreement with numerical simulations. By parameterizing aerosol activation in terms of a critical supersaturation (Twomey, 1959) and critical radius within a lognormal aerosol size distribution (Ghan et al., 1993), Abdul-Razzak et al. (1998) obtained an activation parameterization in terms of all of the parameters of the aerosol size distribution whose activated fraction is within $10 \%$ difference from that of a numerical model for most conditions. AR-G00 updated Abdul-Razzak and Ghan (1998) (which applied to a single lognormal aerosol mode with uniform chemical composition) by enabling its application to an aerosol population represented by multiple lognormal modes, each with a uniform bulk hygroscopicity determined by an internal mixture of chemical components within each mode. As air quality and climate models often characterize aerosols by multiple lognormal modes, AR-G00 has been widely included in many models (see Table 3 in Ghan et al. (2011) for summary).

Another widely used activation parameterization, Fountoukis and Nenes (2005) (hereto referred as FN05), is based on Nenes and Seinfeld (2003) and includes explicit calculations of mass transfer, condensation coefficient, integration over the aerosol size distribution, and kinetic limitations. In order to maintain computational efficiency, the parameterization of Nenes and Seinfeld (2003) split the aerosol population (defined in terms of a sectional size distribution) into two groups: 1) those with diameters that activate near the maxi- mum supersaturation and 2) those with diameters that do not activate near the maximum supersaturation. FN05 updated this parameterization to account for a lognormal aerosol size distribution and size-dependent mass transfer coefficient of water vapor to droplets; it also addresses some of the limitations of AR-G00, especially for conditions when kinetic limitations on droplet nucleation are expected. When strong kinetic limitations occur, the maximum supersaturation is not the same as the critical supersaturation (defined as the saturation at which a particle radius will grow beyond the equilibrium size at the maximum supersaturation). Under these conditions, the relationship between maximum and critical supersaturation is determined empirically in FN05 from numerical simulations for a range of conditions. Another unique feature of FN05 is its ability to account for the influence of gas kinetics on the water vapor diffusivity. This influence depends on particle size and on the value of the condensation coefficient. Fountoukis and Nenes (2005) found that an average value of the diffusivity over an appropriate size range can account for the influence of gas kinetics on droplet nucleation. By expressing the solution in terms of the condensation coefficient, FN05 is applicable to a range of environmental conditions. Unlike AR-G00, FN05 does not approximate functions of the maximum supersaturation and does not rely on empirical relationships (except in the case of strong kinetic limitations across the $\mathrm{CCN}$ population). A disadvantage of FN05 is that it requires iterations to solve for maximum supersaturation which makes it more computationally expensive than AR-G00 (Ghan et al. 2011). In our global simulations, the FN05 scheme increased computational time by $10 \%$ with negligible additional increases for the FN05-based updates. A comprehensive comparison of AR-G00, FN05, and several other activation parameterizations was performed by Ghan et al. (2011), which showed that FN05 predicted the number fraction of activated aerosol in better agreement with a high-confidence numerical solution. Despite their many differences, the implementation of both AR-G00 and FN05 in CAM5.0 resulted in a small difference $\left(0.2 \mathrm{~W} \mathrm{~m}^{-2}, 10 \%\right)$ in the predicted effect of anthropogenic aerosol on shortwave cloud forcing (Ghan et al., 2011).

This study expands upon the work of Ghan et al. (2011) by evaluating the individual processes affecting aerosol activation within an Earth Systems Model with advanced chemistry and aerosol treatments using global scale satellite/groundbased observations. Our objective is to improve the model's representation of aerosol-cloud interactions by incorporating advanced aerosol activation treatments into the Community Atmosphere Model version 5.1.1 within the Community Earth System Model version 1.0.5 (hereto referred as CESM/CAM5) and demonstrating the benefits of such advanced treatments through an initial application of the improved model. 


\section{Model setup}

\subsection{CESM/CAM5 with an advanced aerosol activation module}

In this work, we use CESM/CAM5 to explore the impact of several different aerosol activation schemes on global scale cloud properties and meteorology through aerosol-cloud interactions. The CESM/CAM5 used in this work is a version recently released by the National Center for Atmospheric Research (NCAR) and further developed and improved at North Carolina State University (NCSU) (He and Zhang, 2013). It includes advanced gas-phase chemistry, aerosol nucleation, and inorganic aerosol thermodynamics that are coupled with the seven-mode modal aerosol module (MAM7) in CAM5 (Liu et al., 2012). The gas-phase chemistry is based on the 2005 Carbon Bond chemical mechanism with global extension (CB05_GE) (Karamchandani et al., 2012). The aerosol nucleation is based on a combination of the default nucleation parameterizations of Vehkamaki et al. (2002) and (Merikanto et al., 2007) and a newly added ion-mediated aerosol nucleation (Yu, 2010) above the planetary boundary layer (PBL) and the maximum nucleation rate from among Vehkamaki et al. (2002), Merikanto et al. (2007), Yu (2010), and Wang et al. (2009) parameterizations in the PBL (see He and Zhang (2013) for details). The inorganic aerosol thermodynamics is based on ISORROPIA II (Fountoukis and Nenes, 2007), and explicitly simulates thermodynamics of $\mathrm{SO}_{4}^{2-}, \mathrm{NH}_{4}^{+}, \mathrm{NO}_{3}^{-}, \mathrm{Cl}^{-}$, and $\mathrm{Na}^{+}$as well as the impact of crustal species associated with the fine dust mode. Other updates in the CESM/CAM5 version used in this work include the splitting sea-salt aerosol in MAM7 into sodium and chloride to enable chlorine chemistry in ISORROPIA II and addition of aqueous-phase dissolution and dissociation of $\mathrm{HNO}_{3}$ and $\mathrm{HCl}$. In addition, while the released version of MAM7 uses a constant mass accommodation coefficient of 0.65 for all condensable species, the NCSU's version uses species-dependent accommodation coefficients for $\mathrm{H}_{2} \mathrm{SO}_{4}$, $\mathrm{NH}_{3}, \mathrm{HNO}_{3}$, and $\mathrm{HCl}$, with the value of $0.02,0.097,0.0024$, and 0.005 , respectively.

In the released version of CESM/CAM5, aerosol activation occurs if the liquid cloud fraction either increases with time or elevation (Ghan et al., 1997; Ovtchinnikov and Ghan, 2005), with the number activated in the increasing cloud fraction diagnosed by the AR-G00 scheme as a function of aerosol chemical and physical parameters (as given by MAM7 in this case), temperature, and vertical velocity (Abdul-Razzak and Ghan, 2000). Stratiform cloud microphysics are described by Morrison and Gettelman (2008), which treats both the cloud droplet number concentration and mixing ratio in order to simulate indirect aerosol effects and cloud-aerosol interactions. A bug in the maximum supersaturation calculation in the AR-G00 scheme was recently reported, which has been corrected in our CESM/CAM5 simulation with the AR-G00 scheme. In this work, the NCSU's version of CESM/CAM5-MAM7 is further developed by providing an alternative to the AR-G00 scheme with FN05 and the updates of Kumar et al. (2009) (K09) and Barahona et al. (2010) (B10) to FN05, which account for adsorption activation from insoluble $\mathrm{CCN}$, and giant $\mathrm{CCN}$ equilibrium timescale on aerosol activation. In the K09 parameterization, water vapor is adsorbed onto insoluble particles such as dust and black carbon (BC) whose activity is described by a multilayer Frenkel-Halsey-Hill (FHH) adsorption isotherm. Calculations of the FHH adsorption isotherm in K09 account for particle curvature with atmospherically relevant adsorption parameters. Values of 2.25 and 1.20 are used for the $A_{F H H}$ and $\mathrm{B}_{\mathrm{FHH}}$ empirical constants, respectively (where $\mathrm{A}_{\mathrm{FHH}}$ characterizes the interactions of adsorbed molecules with the aerosol surface and adjacent adsorbate molecules and $\mathrm{B}_{\mathrm{FHH}}$ characterizes the attraction between the aerosol surface and the adsorbate in subsequent layers; Kumar et al., 2009). As insoluble adsorption leads to the activation of some particles which would not easily activate under Köhler theory, a regional increase in the CDNC is expected in clouds affected by high dust or BC concentrations. FHH adsorption activation occurs in addition to Köhler activation in our version of CESM/CAM5, and decreases in CDNC are expected to be rare. The B10 parameterization accounts for the slow condensation upon inertially limited (large) droplets in the calculation of the droplet surface area and maximum supersaturation in a cloud updraft. As the slow condensation (relative to cloud formation timescales) limits the activation of giant $\mathrm{CCN}$, a regional decrease in the CDNC is expected in clouds affected by large sea-salt aerosol and aged-dust concentrations. The simulations with the FN05 scheme and updates use the same interface as that of AR-G00, with an accommodation coefficient value of 0.06 (Fountoukis and Nenes, 2005) and an insoluble fraction of each mode calculated from its hygroscopicity parameter (Petters and Kreidenweis, 2007).

\subsection{Model simulation design and setup}

The CESM/CAM5 baseline simulations are performed using AR-G00 and FN05 for aerosol activation. In addition, three sensitivity simulations are designed to test individually and then collectively the impact of the aforementioned FN05based updated parameterizations on global cloud properties and radiation. During the first two simulations, FN05 is updated individually by K09 and B10 (referred to as FN05/K09 and FN05/B10), respectively. The last simulation contains FN05 with both updates (referred to as FN05/K09/B10). Table 1 summarizes all the simulations completed in this work along with their purposes. The initial conditions for CAM5 are derived from a 10 year (1990-2000) CAM5 stand-alone simulation with the MOZART chemistry provided by NCAR. A 1-year (1 January-31 December 2000) CESM/CAM5 simulation using NCAR's CESM B_18502000_CAM5_CN component set is performed as spin-up to provide the initial conditions for meteorological variables 
Table 1. The CESM/CAM5-MAM7 simulations performed in this study.

\begin{tabular}{|c|c|c|c|c|c|}
\hline Name & $\begin{array}{l}\text { Köhler } \\
\text { activation }\end{array}$ & $\begin{array}{l}\text { Population } \\
\text { spitting }\end{array}$ & $\begin{array}{l}\text { Insoluble } \\
\text { adsorption }\end{array}$ & $\begin{array}{l}\text { Giant CCN } \\
\text { equilibrium }\end{array}$ & $\begin{array}{l}\text { Major differences } \\
\text { and purpose }\end{array}$ \\
\hline AR-G00 & $\checkmark$ & & & & Baseline simulation \\
\hline FN05 & $\checkmark$ & $\checkmark$ & & & $\begin{array}{l}\text { Uses the Fountoukis and Nenes (2005) activation } \\
\text { scheme }\end{array}$ \\
\hline FN05/K09 & $\checkmark$ & $\checkmark$ & $\checkmark$ & & $\begin{array}{l}\text { Uses the Fountoukis and Nenes (2005) activation } \\
\text { scheme updated by Kumar et al. (2009), accounting } \\
\text { for the impact of insoluble adsorption }\end{array}$ \\
\hline FN05/B10 & $\checkmark$ & $\checkmark$ & & $\checkmark$ & $\begin{array}{l}\text { Uses the Fountoukis and Nenes (2005) activation } \\
\text { scheme updated by Barahona et al. (2010), account- } \\
\text { ing for the impact of giant CCN activation kinetics }\end{array}$ \\
\hline FN05/K09/B10 & $\checkmark$ & $\checkmark$ & $\checkmark$ & $\checkmark$ & $\begin{array}{l}\text { Uses the Fountoukis and Nenes (2005) activation } \\
\text { scheme updated by Kumar et al. (2009), and Bara- } \\
\text { hona et al. (2010), accounting for all above aerosol } \\
\text { activation processes }\end{array}$ \\
\hline
\end{tabular}

and chemical species that are treated in both MOZART and CB05_GE. All CESM/CAM5 simulations are performed for the year 2001 with a 3-month (1 October-31 December 2000) spin-up to provide initial conditions for chemical species that are treated in CB05_GE but not in MOZART at a horizontal grid resolution of $0.9^{\circ} \times 1.25^{\circ}$ using the B_1850-2000_CAM5_CN component set, which includes all active components of CESM, 1850 to 2000 transient climate, CAM5 physics, and carbon/nitrogen cycling in the Community Land Model. We selected the coupled version of CESM to realistically simulate the impact of aerosol activation within an Earth Systems framework. While a one-year simulation cannot determine the climate impact of aerosol activation (particularly with an Earth Systems model whose components require significantly longer time periods to reach equilibrium), our objective is to estimate the potential change in magnitude of aerosol radiative forcing from different aerosol activation parameterizations.

The initial chemical conditions are based on those available in the default MOZART, with missing species populated by a one-year spin-up. Anthropogenic emissions and dimethyl sulfide (DMS) emissions are based on the inventory used for the global-through-urban weather and forecasting model with chemistry (GU-WRF/Chem) simulations in Zhang et al. (2012) and with scaled emissions of sulfur dioxide $\left(\mathrm{SO}_{2}\right)$, ammonia $\left(\mathrm{NH}_{3}\right), \mathrm{BC}$, and organic carbon $(\mathrm{OC})$ in the continental U.S., Europe, and east Asia domains based on several recent emission inventories, known uncertainties in those emissions, and initial model evaluation using available observations of surface chemical concentrations (He and Zhang, 2013). Online natural emissions include biogenic volatile organic compounds based on the Model of Emissions of Gases and Aerosols from Nature (MEGAN) scheme version 2 (Guenther et al., 2006; Heald et al., 2008), dust based on the Dust Entrainment and Deposition scheme of Zender et al. (2003), and sea-salt aerosol based on Mårtensson et al. (2003) for particles $<2.8 \mu \mathrm{m}$ in dry diameter and Monahan et al. (1986) for particles $\geq 2.8 \mu \mathrm{m}$ in dry diameter.

\subsection{Model evaluation data sets and protocol}

Model performance is evaluated for both radiative and meteorological predictions from available surface and satellite observations for the year 2001, including aerosol optical depth (AOD), CCN, CDNC, cloud fraction (CF), cloud optical thickness (COT), liquid water path (LWP), shortwave cloud forcing (SWCF), downward shortwave radiation (SWDOWN), downward longwave radiation (LWDOWN), outgoing longwave radiation (OLR), surface precipitation (from the Global Precipitation Climatology Project) and 10 meter wind speed (from the National Climatic Data Center data set). Satellite data sets are derived from the Moderate Resolution Imaging Spectroradiometer (MODIS) collection 5.1 and the Clouds and Earth's Radiant Energy System (CERES) sensors aboard the Terra satellite. Global surface radiation data is from the Baseline Surface Radiation Network (BSRN). In addition to the MODIS-derived CDNC (Bennartz, 2007), a data set of CDNC compiled mostly from field campaigns (Karydis et al., 2011) is included. CDNC is calculated as an average value of layers between 960 to 850 $\mathrm{mb}$ for comparison with the satellite-derived values of Bennartz (2007) and is extracted for the $930 \mathrm{mb}$ layer (near the top of the boundary layer) for comparison with the data set from Karydis et al. (2011) and references therein. The protocols for performance evaluation follow those used in Zhang et al. (2012), focusing on the annual-averaged normalized mean bias (NMB) and correlation coefficient. 
Table 2. Annual mean normalized mean biases (NMBs, in \%) of the CESM-CAM5-predicted meteorological/radiative variables.

\begin{tabular}{llrrrrr}
\hline Variable & Data set & AR-G00 & FN05 & FN05/K09 & FN05/B10 & FN05/K09/B10 \\
\hline AOD & MODIS & -33.9 & -32.3 & -31.7 & -30.8 & -31.6 \\
CCN & MODIS & -66.7 & -80.6 & -80.9 & -81.2 & -81.2 \\
CDNC & Bennartz (2007) & -44.3 & 28.0 & 37.4 & 10.2 & 16.0 \\
& Karydis et al. (2011) & -69.2 & -23.5 & -21.5 & -40.6 & -24.4 \\
CF & MODIS & -0.5 & 0.5 & 0.9 & 0.7 & 0.0 \\
COT & MODIS & -55.6 & -41.1 & -40.3 & -43.0 & -41.9 \\
LWP & MODIS & -75.6 & -66.9 & -66.8 & -67.8 & -67.2 \\
SWCF & CERES & -2.1 & 13.0 & 13.1 & 11.3 & 11.2 \\
SWDOWN & BSRN & 3.7 & -5.3 & -6.1 & -5.4 & -5.3 \\
LWDOWN & BSRN & -0.9 & -3.0 & -2.5 & -2.4 & -2.5 \\
OLR & NOAA-CDC & 3.2 & 2.2 & 2.2 & 2.3 & 2.5 \\
Precipitation & GCPC & 11.3 & 8.5 & 8.7 & 8.9 & 9.3 \\
Wind Speed & NCDC & -16.1 & -15.2 & -14.7 & -14.8 & -14.2 \\
\hline
\end{tabular}

Table 3. Annual mean correlation coefficients of the CESM-CAM5-predicted meteorological/radiative variables.

\begin{tabular}{llrrrrr}
\hline Variable & Data set & AR-G00 & FN05 & FN05/K09 & FN05/B10 & FN05/K09/B10 \\
\hline AOD & MODIS & 0.66 & 0.65 & 0.65 & 0.65 & 0.66 \\
CCN & MODIS & 0.49 & 0.37 & 0.37 & 0.37 & 0.37 \\
CDNC & Bennartz (2007) & 0.54 & 0.55 & 0.58 & 0.55 & 0.58 \\
& Karydis et al. (2011) & -0.10 & 0.16 & 0.24 & 0.10 & 0.26 \\
CF & MODIS & 0.71 & 0.72 & 0.71 & 0.71 & 0.71 \\
COT & MODIS & -0.17 & -0.16 & -0.15 & -0.14 & -0.14 \\
LWP & MODIS & -0.38 & -0.37 & -0.37 & -0.36 & -0.36 \\
SWCF & CERES & 0.88 & 0.90 & 0.89 & 0.90 & 0.90 \\
SWDOWN & BSRN & 0.90 & 0.91 & 0.91 & 0.90 & 0.90 \\
LWDOWN & BSRN & 0.98 & 0.97 & 0.98 & 0.98 & 0.98 \\
OLR & NOAA-CDC & 0.97 & 0.97 & 0.97 & 0.97 & 0.97 \\
Precipitation & GCPC & 0.80 & 0.76 & 0.77 & 0.78 & 0.79 \\
Wind Speed & NCDC & 0.40 & 0.41 & 0.41 & 0.41 & 0.41 \\
\hline
\end{tabular}

\section{Results}

\subsection{Global performance statistics}

Table 2 and 3 summarize model performance statistics for aerosol, cloud, and radiative predictions of CESM/CAM5 with various aerosol activation schemes over the global domain. AOD is underpredicted by all simulations, with little change in the NMB (ranging from -34.0 to $-30.8 \%$ ) and correlations $(\sim 0.64)$ among the simulations. The underprediction of AOD is likely due to both underpredictions of terrestrial/anthropogenic aerosol concentrations ( $\mathrm{He}$ and Zhang, 2013) and overestimates of oceanic AOD in the MODIS collection 5.1 (Levy et al., 2013). The small change in AOD among the simulations is likely due to changes in meteorological parameters such as surface winds and precipitation which can affect the emission, transport, and lifetime of aerosols (Zhang, 2008). Although CESM-CAM5 underpredicts (NMB $<-66.7 \%)$ column CCN concentrations at $0.5 \%$ supersaturation compared to MODIS-derived values, the difficulty in using remote sensing measurements for the estimation of CCN abundances (Andreae, 2009) makes interpretation uncertain.

CDNC, unlike AOD, is strongly influenced by the selection of aerosol activation scheme. The AR-G00 simulation gives an NMB of -44.3 and $-69.2 \%$ for the satellitederived and in-situ observations, respectively. For comparison, the CDNC from the FN05 simulation and all sensitivity simulations with updated activation treatments is either less underpredicted or becomes overpredicted with a NMB of 10.2 to $37.4 \%$ and -40.6 to $-21.5 \%$ for the satellitederived and in situ observations, respectively. The higher CDNC predicted by the FN05 simulation relative to ARG00 is consistent with results from Ghan et al. (2011) and Zhang et al. (2012), who attribute the difference to the tendency of the FN05 scheme to diagnose higher activation fractions than the AR-G00 scheme for most environmental conditions. The higher activation fraction in FN05 relative to AR-G00 is primarily due to the different values of the effective uptake coefficient used in FN05 (0.06) and AR-G00 
(1.0 or higher) (Zhang et al., 2012). Improvement in CDNC predictions (relative to observations) from the FN05 scheme in many regions is consistent with the Ghan et al. (2011) results, showing that the FN05 activated fraction is more similar than that of AR-G00 to a numerical solution for marine, clean continental, and background aerosol distributions for a range of updraft velocities. It should be noted, however, that regions with low CDNC tend to be overestimated by the FN05 scheme. Compared to the satellite-based CDNC data set, FN05/K09 has the highest overprediction and FN05/B10 has the lowest overprediction among the all FN05-based simulations. These trends are expected, as insoluble adsorption in FN05/K09 leads to additional activation in regions with high dust/BC concentrations while giant $\mathrm{CCN}$ activation kinetics leads to less activation in regions with high dust/sea spray concentrations. Among the two processes (insoluble adsorption and giant $\mathrm{CCN}$ activation kinetics) updated in the FN05 scheme, giant CCN activation kinetics in FN05/B10 seems to be the most globally significant, leading to larger changes from the FN05 simulation and determining the sign of CDNC predictions in the FN05/K09/B10 simulation relative to FN05. Correlations between the satellite-derived/insitu observed CDNC and CESM/CAM5 predictions improve from AR-G00 to the FN05 series of simulations (with correlations of 0.54 to $0.55-0.60$ and -0.10 to $0.10-0.26$ for the satellite-derived and in-situ observations, respectively). Based on correlations, the FN05/K09/B10 simulation combining all of the activation mechanism updates has the best agreement with the two CDNC data sets.

Changes in CDNC produced by different aerosol activation schemes have an impact on the predicted cloud properties such as cloud fraction, optical thickness, liquid water path, and shortwave cloud forcing. Although all model simulations predict cloud fraction very well (with NMBs from -0.5 to $0.9 \%$ ), there is a consistent underprediction in the mid-latitudes and tropics (see Fig. 1). The correlation between satellite-derived and predicted cloud fraction is essentially the same for all simulations at $\sim 0.71$. Significant underpredictions occur in COT (with NMB of -55.6 to $-40.3 \%$ ) and LWP (with NMB of -75.6 to $-66.8 \%$ ) for all simulations (see Fig. 1). The COT and LWP underpredictions are consistent with those of Gettelman et al. (2010) and Liu et al. (2011) who found that the predictions are most sensitive to dust loading and attributed the CAM5 underpredictions to a severe underestimation of aerosol concentrations in CAM5 in the Arctic (and likely Antarctic) regions. Underpredictions in COT and LWP may also be caused by limitations and uncertainties associated with the microphysics modules for convective clouds. For both COT and LWP, the inclusion of the FN05 scheme and updates reduces the underpredictions moderately but does not improve the poor correlation $(<-0.14)$. The additional CDNC predicted by the FN05 scheme acts similarly to the impact from anthropogenic aerosols; increasing the aerosol activation fraction is equivalent to adding more aerosols in the calculation of
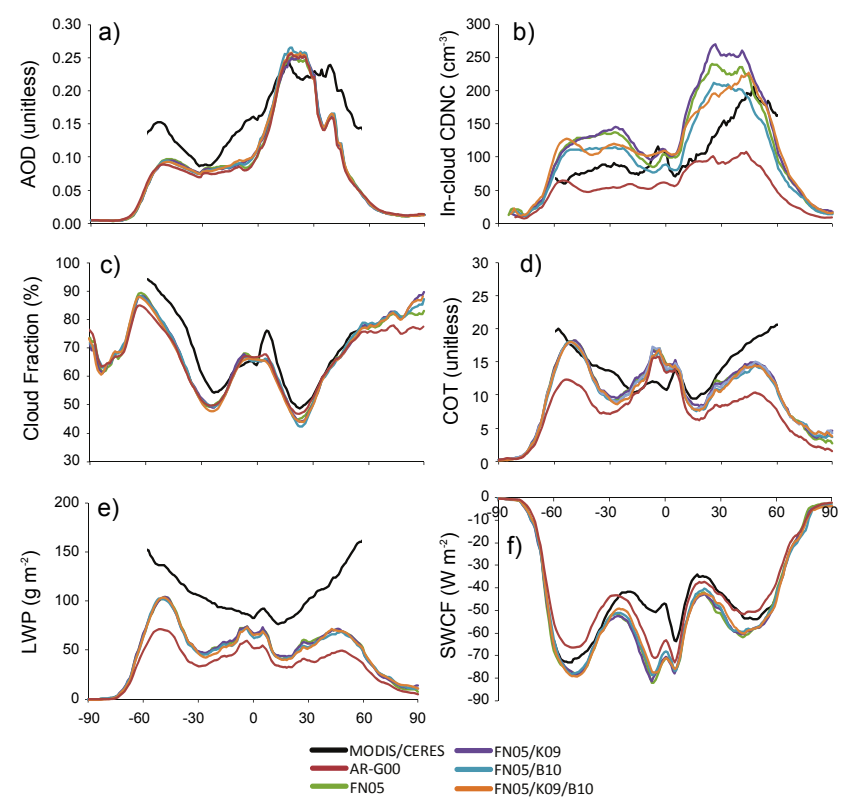

Figure 1. Annual-average zonal-mean (a) aerosol optical depth, (b) low level cloud droplet number concentration (MODIS values derived from Bennartz (2007) and CESM/CAM5 values averaged between 960 and $850 \mathrm{mb}$ ), (c) cloud fraction, (d) cloud optical thickness, (e) liquid water path, and (f) shortwave cloud forcing derived from satellites and predicted by CESM/CAM5.

cloud albedo and cloud lifetime effects. Similar to cloud fraction, comparison of satellite-derived and predicted SWCF reveals that the FN05 scheme and updates change the slight underprediction (with an NMB of $-2.1 \%$ ) for the AR-G00 simulation to moderate overpredictions (with NMBs from 11.2 to $13.1 \%$ ), increasing (more negative) the global average SWCF by -5.0 to $-5.7 \mathrm{~W} \mathrm{~m}^{-2}$. Despite worsening the bias, the inclusion of the FN05 updates does not significantly change the correlations ( 0.88 to 0.90$)$. Although it has large underpredictions in LWP and COT, the AR-G00 simulation has relatively accurate predictions of SWDOWN, LWDOWN, and OLR because CAM5 has been highly tuned with AR-G00 to produce a small NMB for SW flux. The slight overprediction of SWDOWN and underprediction and LWDOWN (with NMBs of 3.7 and $-0.9 \%$, respectively) in AR-G00 become all underpredictions in the FN05 series of simulations (with NMBs of -6.1 to $-5.3 \%$ and -3.0 to $-2.4 \%$ ). The larger underprediction of SWDOWN in the FN05 series of simulations is likely associated in part with the overprediction in $\mathrm{CF}$ and in part with increases in CDNC, LWP, and COT. The overprediction of OLR for the AR-G00 simulation, however, is reduced by the FN05 series of simulations. Although the climate impact of aerosol activation cannot be determined from our one-year coupled atmosphere-ocean simulations, the overprediction of precipitation and underprediction of $10 \mathrm{~m}$ wind speed from AR-G00 were slightly reduced (by $\sim 2 \%$ ) in FN05/K09/B10 due to 
MODIS

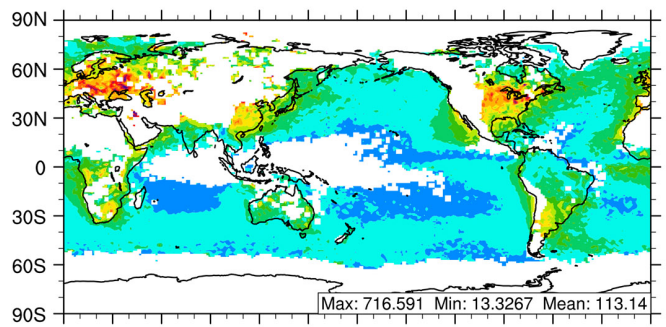

FN05

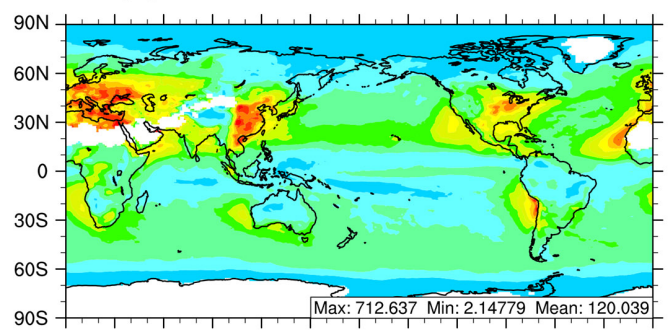

FN05/B10

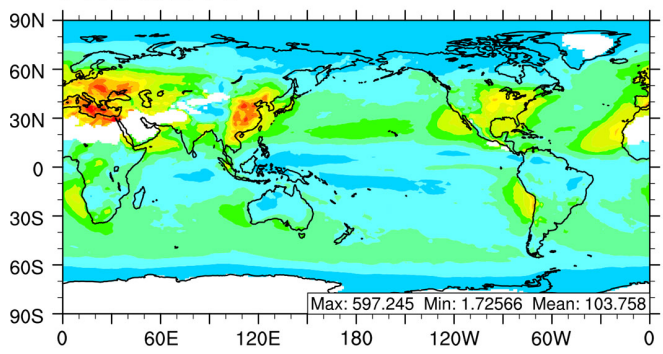

AR-G00

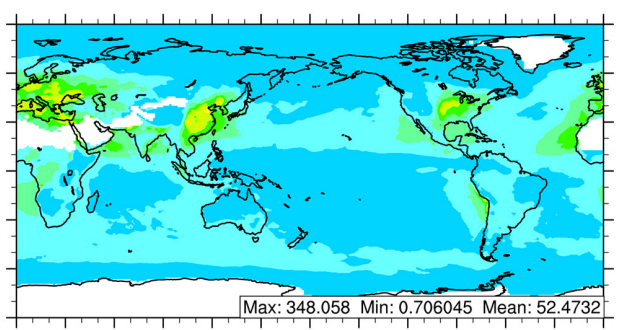

\section{FN05/K09}

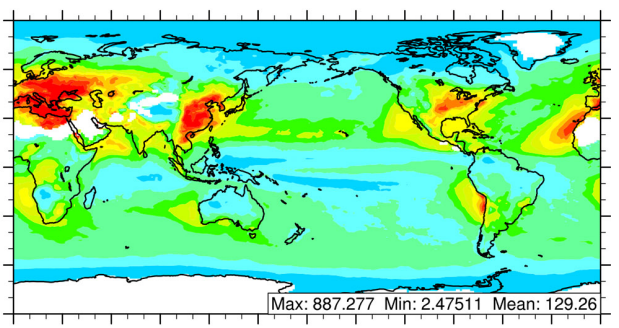

FN05/K09/B10

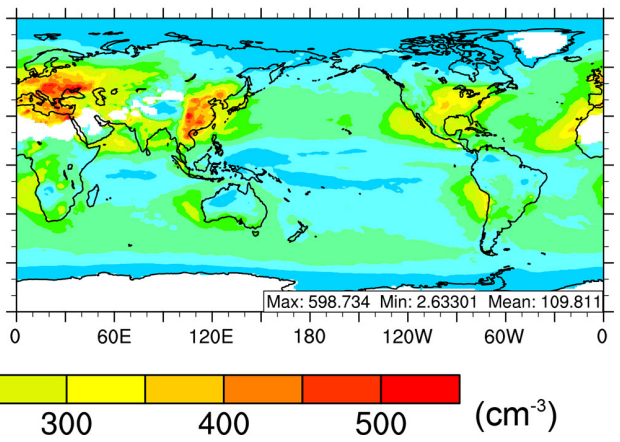

Figure 2. Annual average low-level CDNC from MODIS (Bennartz, 2007) and CESM/CAM5 (averaged between 960 to $850 \mathrm{mb}$ ) simulations.

small modifications of meteorology from the different activation schemes.

\subsection{Regional impacts of aerosol activation treatments}

\subsubsection{Aerosol optical depth and cloud droplet number concentration}

Like the global averages, the zonal average AOD differences between the simulations are relatively insensitive (differences $<0.01$ ) to the choice of aerosol activation schemes. Much of the underprediction by all model simulations in the Southern Hemisphere from -60 to $-40^{\circ}$ is due to a bias in satellite products (i.e., MODIS Collection 5.1), which does not account for the wind speed-dependent whitecap and foam fraction on the ocean surface (Levy, 2013). Zonal-average CDNC, on the other hand, is very sensitive to the different activation schemes. The largest differences in CDNC predicted by the AR-G00 and FN05 series of simulations are in the mid-latitudes (from $-50^{\circ}$ to $-20^{\circ}$ and $20^{\circ}$ to $50^{\circ}$ ), where the AR-G00 underpredicts CDNC by 10 to $50 \mathrm{~cm}^{-3}$ and the FN05 series of simulations overpredict CDNC by $25-50 \mathrm{~cm}^{-3}$ compared to the MODIS-derived data set. The CDNC underprediction from the AR-G00 simulation may be related in part to aerosol abundance, which is underpredicted by all of the simulations compared to MODIS-derived AOD (see Fig. 1) in the mid-latitudes. Like model predictions of global-average CDNC, the higher zonal CDNC in the FN05 series of simulations (relative to AR-G00) can be attributed to the different values of the effective uptake coefficient used in FN05 and AR-G00 (Zhang et al., 2012). Among the FN05 series of simulations, the zonal-average CDNC is the highest for the FN05 and FN05/K09 simulations and the lowest (closer to the MODIS-derived values) for the FN05/B10 and FN05/K09/B10 simulations. The slightly higher global correlation between the satellite and model predicted CDNC for the FN05/K09 and FN05/K09/B10 simulations can be attributed to the higher CDNC from insoluble adsorption in regions with large dust emissions (centered around $-30^{\circ}$ for deserts in southern Africa, Australia, and Patagonia and $30^{\circ}$ for the Sahara, Arabian, and Sonoran deserts). Figure 2 shows that CDNC predicted by 

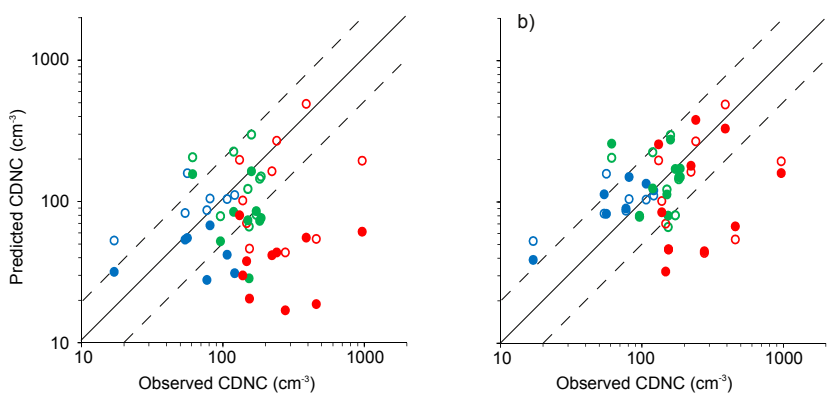

Figure 3. Comparison of CESM/CAM5-predicted (at $\sim 930 \mathrm{mb}$ ) and observed low-level CDNC from field campaigns in clean marine (blue), polluted marine (green), and continental (red) environments as classified and summarized by Karydis et al. (2011). The filled circles are for the (a) AR-G00 and (b) FN05 simulations and hollow circles for the FN05/K09/B10 simulation. Data points where predicted $\mathrm{CDNC}<10 \mathrm{~cm}^{-3}$ were not included. The $1: 1$ and 1:2/2:1 lines are the solid and dotted black lines, respectively.

the AR-G00 simulation is most similar to MODIS-derived CDNC over oceanic regions, while the FN05 series of simulations better predict CDNC over continental areas. This result is consistent with that of Fig. 3a, where a comparison of field campaign-observed CDNC and predictions from the AR-G00 and FN05/K09/B10 simulations reveal a substantial improvement in FN05/K09/B10 for continental regions which are significantly underpredicted in AR-G00. The large improvement (relative to AR-G00) in continental regions from the FN05/K09/B10 simulation results mainly from the higher activation fraction in the FN05 scheme and larger fraction of insoluble aerosols that can be activated in the K09 scheme (see Fig. 3a for comparison). The overpredictions in clean marine CDNC from the FN05 simulation are reduced in the FN05/K09/B10 simulation (see Fig. 3b) because of the inclusion of giant sea spray aerosol activation kinetics which accounts for the slow condensation of water on these particles.

Separating the aerosol activation processes involved in the FN05/K09/B10 simulation shows that the processes have unequal impacts on CDNC resulting in different spatial distributions of column CDNC changes. With the inclusion of the FN05 activation scheme, most areas (with the exception of desert regions in northern Africa, Arabian Peninsula, and Antarctica) experience an increase in column CDNC (Fig. 4). The largest increases in column CDNC occur in regions near or downwind of population centers in China, US, and Europe. As a percentage, however, the largest changes occur over the Tibetan Plateau, the western US, Greenland, and remote Pacific Ocean where CDNC is low. Globally, the average increase in CDNC from the AR-G00 simulation to the FN05 simulation is $167 \%$. This increase is substantially larger than the 20-50\% increase reported by Ghan et al. (2011) for CAM5 but closer in magnitude (although larger) to the $100 \%$ increase reported by Zhang et al. (2012) for GU-WRF/Chem. Such differences can be attributed to differences in mass accommodation coefficients of water vapor used (1.0 in AR-G00 vs. 0.06 in FN05), methods in solving max supersaturation $\left(S_{\max }\right)$ (AR-G00 uses a semiempirical relationship to approximate $S_{\max }$, whereas FN05 uses numerical iterations to solve $S_{\max }$ ), and the temperature dependence in the calculation of Kelvin effects (temperature dependence is neglected in AR-G00 but accounted for in FN05).

While similar to FN05 in the magnitude of CDNC change from AR-G00, the FN05/K09 simulation has higher percentage changes in CDNC over many desert regions such the Saharan and Arabian Deserts (see Fig. 5) leading to a global average increase of $183 \%$. This additional increase is the result of insoluble $\mathrm{CCN}$ activating into cloud droplets that would not activate according to Köhler theory on which the AR-G05 and FN05 are based. Accounting for giant CCN activation kinetics in FN05/B10 leads to lower CDNC relative to FN05, especially over the remote marine and desert regions (Fig. 5) where sea-salt aerosol and dust are important $\mathrm{CCN}$ sources. Because of the large fraction of the Earth covered by oceans, the FN05/B10 scheme has a globallysignificant impact on average column CDNC (the average increase from AR-G00 decreases from $167 \%$ in FN05 to $136 \%$ in FN05/B10). Both the FN05/K09 and FN05/B10 simulations also experience isolated regions in which the CDNC change is opposite to the expected (from box model simulations) trend, likely located within transitional regimes as described by Reutter et al. (2009) where cloud droplet formation is sensitive to both aerosol activation and updraft velocity. Combined, the effects of insoluble adsorption and giant $\mathrm{CCN}$ activation kinetics lead to a predicted change in column CDNC from the FN05 scheme that is higher than FN05 over desert regions, slightly lower over much of the ocean, and relatively unchanged areas like the continental US, China, and Europe where either the concentration of insoluble aerosols and giant $\mathrm{CCN}$ are low or their impacts compensate for each other (see Fig. 5). Compared with the AR-G00 simulation, the FN05/K09/B10 simulation combining all of the activation updates has a global average percent change in column CDNC of $150 \%$. With the exception of polluted regions in China, eastern Europe, and eastern US, these changes in CDNC are greater than the internal model variability as determined by the seasonal standard deviation from the AR-G00 simulation.

\subsubsection{Cloud properties}

Unlike CDNC which is sensitive to both the implementation of the FN05 scheme and the subsequent updates, changes in zonal-average cloud fraction, COT, and LWP are relatively small and noticeable only by the transition from the AR-G00 to the FN05 series of simulations (see Fig. 1). Incremental changes are predicted for the cloud fraction predictions from different aerosol activation schemes, with the largest changes 


\section{Column CDNC (left: $\mathrm{cm}^{-2}$, right: \%)}
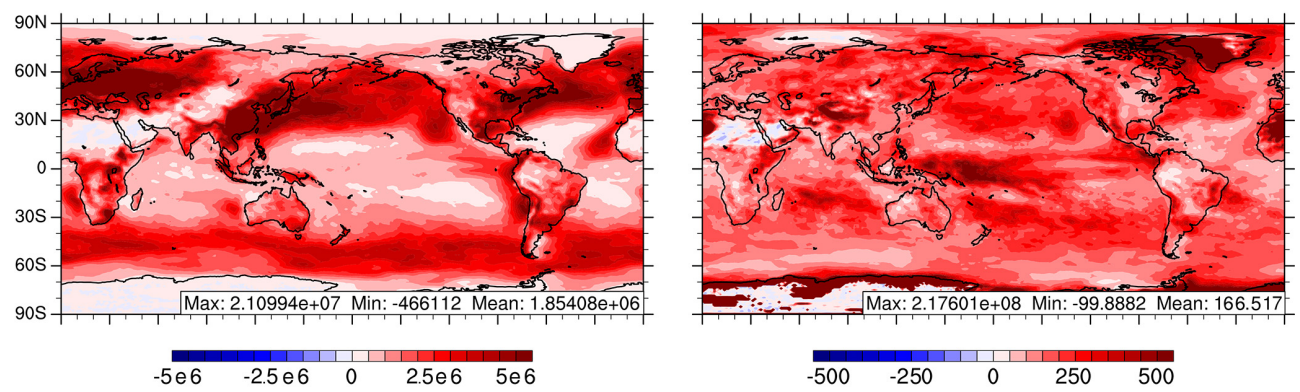

Shortwave Cloud Forcing (left: $\mathrm{W} \mathrm{m}^{-2}$, right: \%)
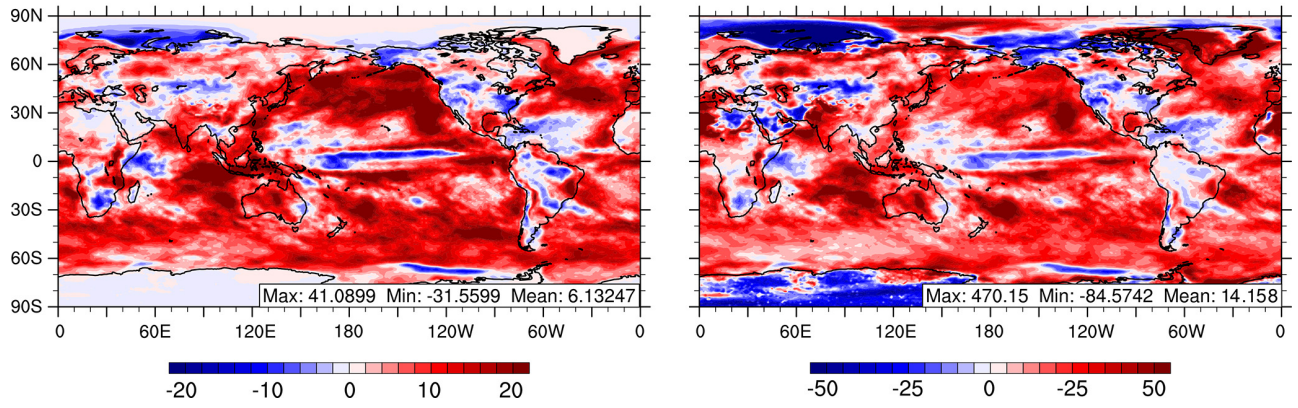

Figure 4. Annual-average absolute and percentage changes from the FN05 and AR-G00 CESM/CAM5 simulations for column CDNC and shortwave cloud forcing. Because the shortwave cloud forcing typically has negative values, the absolute change map (bottom left) uses $|\mathrm{SWCF}|$ so that the warmer colors represent an increase in the forcing even though they are more negative values. The global mean percentage change values are calculated from the averaged absolute change rather than the average of the gridded percentage changes.

occurring in the Arctic where clouds are sensitive to ice nucleation (Xie et al., 2013; Engström et al., 2014). Figure 1 shows that the large underpredictions in COT and LWP by AR-G00 for mid-latitude regions $\left(30-60^{\circ} \mathrm{N} / \mathrm{S}\right)$ are significantly reduced by the implementation of the FN05 series of simulations. In tropical regions, all simulations have the lowest bias in COT and LWP compared to satellite observations and there exists little difference between the model simulations. The insensitivity of tropical cloud properties to the various aerosol activation parameterizations is likely due to the abundance of convective clouds not treated by the aerosol activation schemes and high frequency of strong updrafts in the region which have been shown to have a lower variance in the activated fraction from different parameterizations than do weak updrafts (Ghan et al., 2011). Predictions of CF, COT, and LWP in the AR-G00 and FN05 series of simulations are most different in polar regions because of the sensitivity of Arctic and Antarctic CDNC (and corresponding cloud properties) to slight changes in aerosol and ice nuclei number concentration and lack of sensitivity to aerosol activation treatment (Liu et al., 2011; Moore et al., 2013). Mixedphase clouds, which are found in polar regions, are particularly difficult to simulate because they are affected by both aerosol activation and ice nucleation (Lance et al., 2011; Xie et al., 2013). Ignoring polar regions which have mixed-phase clouds, the moderate underpredictions of CF, COT, and LWP in the AR-G00 are consistently reduced in the FN05 series of simulations.

Changes in cloud fraction, COT, and LWP affect the potential climatic impact of aerosols, as shown by the changes in SWCF (see Figs. 1 and 4). The difference in SWCF between the AR-G00 and FN05 simulations is the highest in the mid-latitudes where the large CDNC differences occur. In mid-latitude regions from -60 to $-30^{\circ}$, the transition from the AR-G00 to the FN05 activation schemes changes the sign of the model bias from negative to positive (see Fig. 1). Globally, the largest changes in SWCF between the AR-G00 and FN05 simulations occur over the oceans, where widespread areas experience a $25 \%$ increase (larger by $10 \mathrm{~W} \mathrm{~m}^{-2}$ in magnitude) in SWCF (see Fig. 4). This sensitivity of radiative forcing in oceanic regions to aerosol activation is due to two main reasons: (1) the low penetration of shortwave radiation through stratocumulus decks covering large areas of the ocean and (2) the sensitivity of marine cloud albedo to changes in CDNC (Twomey, 1991; Platnick and Twomey, 1994; Moore et al., 2013). The updates to the FN05 scheme do not substantially affect the spatial distribution of SWCF changes relative to the change from AR-G00 to FN05. Because the various Earth System components of CESM interact in our simulations, these predicted changes in cloud 

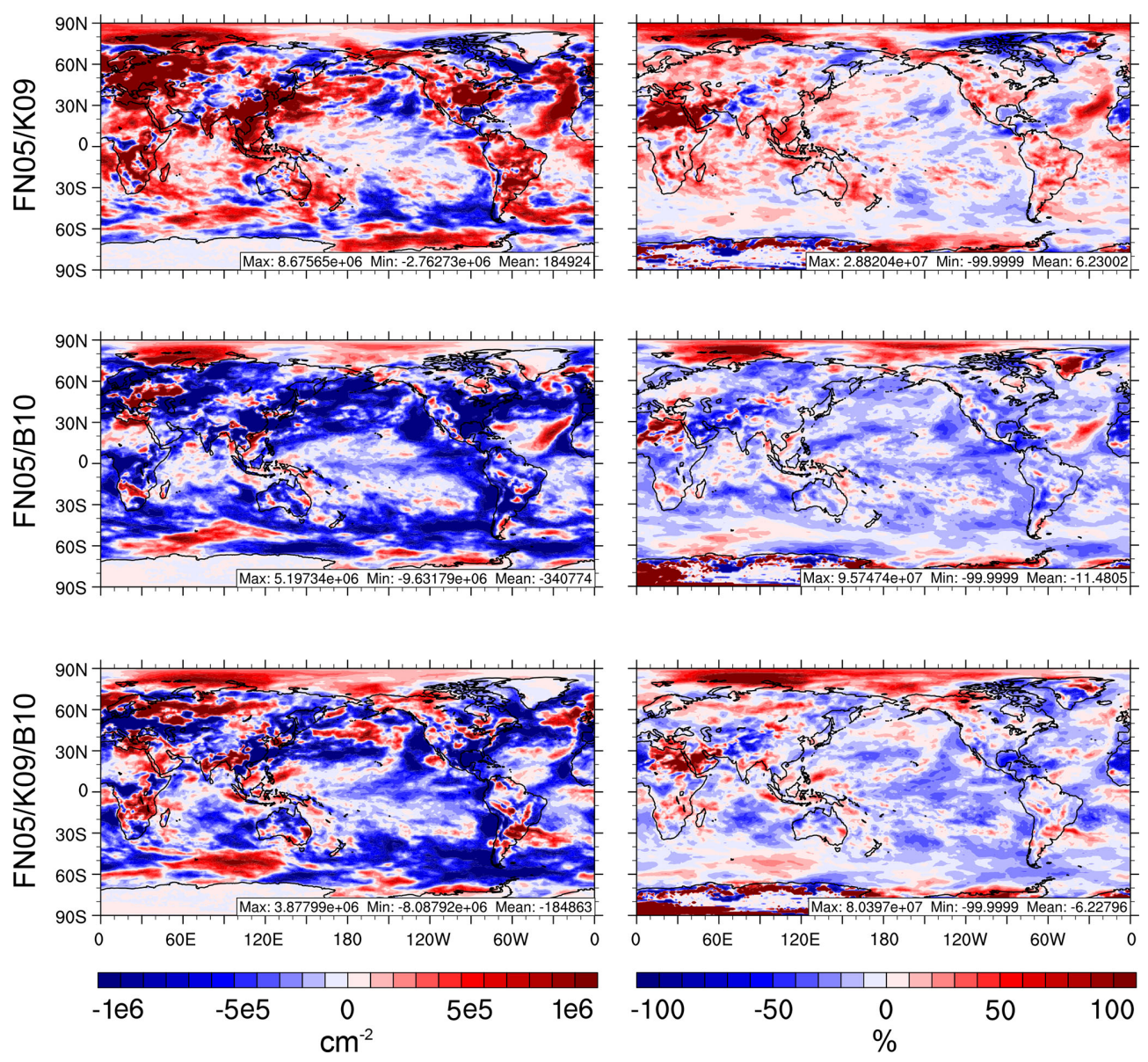

Figure 5. Annual-average absolute (left, in units of $\mathrm{cm}^{-2}$ ) and percentage (right) change in column CDNC from FN05 to each of the FN05 updates in CESM/CAM5. The global mean percentage change values are calculated from the averaged absolute change rather than the average of the gridded percentage changes. Note that the color bar range for the left column is a factor of 5 less than that of Figure 4 (top left) to better show spatial details.

properties (which are statistically significant with a probability value from a student's $t$ test $\ll 0.05$ ) cannot be entirely attributable to aerosol activation. A significantly longer simulation time period and/or prescribed ocean surface conditions are needed to reduce the impact of ocean-atmosphere-cloud feedbacks existing in our simulations.

\section{Conclusions}

In this study, several process-based aerosol activation schemes are implemented into the Community Atmosphere Model version 5.1.1 within the Community Earth System Model version 1.0.5 (CESM/CAM5) to determine the global impacts of individual activation processes on cloud properties. Compared to simulations using the default AbdulRazzak and Ghan (2000) aerosol activation parameterization, simulations with the Fountoukis and Nenes (2005) scheme and updates for insoluble aerosol adsorption (Kumar et al., 2009 ) and giant cloud condensation nuclei ( $\mathrm{CCN})$ activa- tion kinetics (Barahona et al., 2010) are slower ( $\sim 10 \%$ increase in computational time) but have improved predictions of cloud droplet number concentration (CDNC), cloud optical thickness, and liquid water path in many regions. The inclusion of these updates leads to a widespread large increase in CDNC with localized enhancement of CDNC over desert regions and depression of CDNC over oceanic regions. The increase in CDNC predicted by the simulations with updated aerosol activation results in a decrease (more negative) in the global-average shortwave cloud forcing and surface shortwave radiation. In regions where these updates lead to more accurate prediction of CDNC, cloud optical thickness, and liquid water path, we have increased confidence in the predicted magnitude of the radiative forcing from aerosol-cloud interactions. While this study estimates the impact of aerosol activation on cloud properties within an Earth Systems model, determining the climate impact requires a longer simulation period and more comprehensive treatments of aerosol-cloud interactions. Future studies on the interaction between aerosol activation and cloud 
microphysics could be improved through the direct coupling of convection and aerosol activation (Song et al., 2012), inclusion of entrainment on aerosol activation (Barahona and Nenes, 2007), modification of the Nenes and Seinfeld (2003) population splitting concept (Morales Betancourt and Nenes, 2014), and by simulating longer time periods to allow for the various components of the Earth Systems model to approach equilibrium.

Acknowledgements. This project is sponsored by the National Science Foundation EaSM program (AGS-1049200). AN acknowledges support from DOE EaSM and NASA MAP grants. Thanks are due to Ralf Bennartz, Department of Earth and Environmental Sciences, Vanderbilt University, for providing derived CDNC data derived based on MODIS measurements. The GPCP combined precipitation data were developed and computed by the NASA/Goddard Space Flight Center's Laboratory for Atmospheres as a contribution to the GEWEX Global Precipitation Climatology Project. We would like to acknowledge high-performance computing support from Yellowstone (ark:/85065/d7wd3xhc) provided by NCAR's Computational and Information Systems Laboratory, sponsored by the National Science Foundation. We also acknowledge Steven Ghan and the anonymous reviewer for their helpful and insightful comments.

Edited by: H. Tost

\section{References}

Abdul-Razzak, H., Ghan, S., and Rivera-Carpio, C.: A parameterisation of aerosol activation. Part I: Single aerosol type, J. Geophys. Res., 103, 6123-6132, doi:10.1029/97JD03735, 1998.

Abdul-Razzak, H. and Ghan, S. J.: A parameterization of aerosol activation: 2. Multiple aerosol types, J. Geophys. Res., 105, 68376844, 2000.

Albrecht, B. A.: Aerosols, cloud microphysics, and fractional cloudiness, Science, 245(4923), 1227-1230, doi:10.1126/science.245.4923.1227, 1989.

Andreae, M. O.: Correlation between cloud condensation nuclei concentration and aerosol optical thickness in remote and polluted regions, Atmos. Chem. Phys., 9, 543-556, doi:10.5194/acp-9-543-2009, 2009.

Barahona, D. and Nenes, A.: Parameterization of cloud droplet formation in large-scale models: including effects of entrainment, J. Geophys. Res., 112, D16206, doi:10.1029/2007JD008473, 2007.

Barahona, D., West, R. E. L., Stier, P., Romakkaniemi, S., Kokkola, H., and Nenes, A.: Comprehensively accounting for the effect of giant $\mathrm{CCN}$ in cloud activation parameterizations, Atmos. Chem. Phys., 10, 2467-2473, doi:10.5194/acp-10-2467-2010, 2010.

Bennartz, R.: Global assessment of marine boundary layer cloud droplet number concentration from satellite, J. Geophys. Res.Atmos., 112, D02201, doi:10.1029/2006JD007547, 2007.

Boucher, O., Randall, D., Artaxo, P., Bretherton, C., Feingold, G., Forster, P., Kerminen, V.-M., Kondo, Y., Liao, H., Lohmann, U., Rasch, P., Satheesh, S.K., Sherwood, S., Stevens, B., and Zhang, X. Y.: Clouds and Aerosols. In: Climate Change 2013: The Physical Science Basis. Contribution of Working Group I to the Fifth
Assessment Report of the Intergovernmental Panel on Climate Change, edied by: Stocker, T. F., Qin, D., Plattner, G.-K., Tignor, M., Allen, S. K., Boschung, J., Nauels, A., Xia, Y., Bex, V., and Midgley, P. M., Cambridge University Press, Cambridge, UK and New York, NY, USA, 2013.

Chuang, P. Y., Charlson, R. J., and Seinfeld, J. H.: Kinetic limitations on droplet formation in clouds, Nature, 390, 594-596, doi:10.1038/37576, 1997.

Engström, A., Karlsson, J., and Svensson, G.: , The importance of representing mixed-phase clouds for simulating distinctive atmospheric states in the Arctic, J. Clim., 27, 265-272, 2014.

Fountoukis, C. and Nenes, A.: Continued development of a cloud droplet formation parameterization for global climate models, J. Geophys. Res., 110, D11212, doi:10.1029/2004jd005591, 2005.

Gettelman, A., Liu, X., Ghan, S. J., Morrison, H., Park, S., Conley, A. J., Klein, S. A., Boyle, J., Mitchell, D. L., and Li, J. L. F.: Global simulations of ice nucleation and ice supersaturation with an improved cloud scheme in the Community Atmosphere Model, J. Geophys. Res., 115, D18216, doi:10.1029/2009jd013797, 2010.

Ghan, S. J., Leung, L. R., Easter, R. C., and Abdul-Razzak, H.: Prediction of droplet number in a general circulation model, J. Geophys. Res., 102, 21777-21794, 1997.

Ghan, S. J., Abdul-Razzak, H., Nenes, A., Ming, Y., Liu, X., Ovchinnikov, M., Shipway, B., Mekhidze, N., Xu, J., and Shi, X.: Droplet nucleation: Physically-based parameterizations and comparative evaluation, J. Adv. Model. Earth Syst., 3, M10001, doi:10.1029/2011MS000074, 2011.

Guenther, A., Karl, T., Harley, P., Wiedinmyer, C., Palmer, P. I., and Geron, C.: Estimates of global terrestrial isoprene emissions using MEGAN (Model of Emissions of Gases and Aerosols from Nature), Atmos. Chem. Phys., 6, 3181-3210, doi:10.5194/acp-63181-2006, 2006.

He, J. and Zhang, Y.: Improvement and further development in CESM/CAM5: gas-phase chemistry and inorganic aerosol treatments, Atmos. Chem. Phys. Discuss., 13, 27717-27777, doi:10.5194/acpd-13-27717-2013, 2013.

Heald, C. L., Henze, D. K., Horowitz, L. W., Feddema, J., Lamarque, J. F., Guenther, A., Hess, P. G., Vitt, F., Seinfeld, J. H., Goldstein, A. H., and Fung, I.: Predicted change in global secondary organic aerosol concentrations in response to future climate, emissions, and land use change, J. Geophys. Res.-Atmos., 113, D05211, doi:10.1029/2007JD009092, 2008.

Karamchandani, P., Zhang, Y., Chen, S. Y., and Balmori-Bronson, R.: Development and testing of an extended chemical mechanism for global through-urban applications, Atmos. Pollut. Res., 3, 124, doi:10.5094/APR.2011.047, 2012.

Karydis, V. A., Kumar, P., Barahona, D., Sokolik, I. N., and Nenes, A.: On the effect of dust particles on global cloud condensation nuclei and cloud droplet number, J. Geophys. Res., 116, D23204, doi:10.1029/2011jd016283, 2011.

Khain, A. P., BenMoshe, N., and Pokrovsky, A.: Factors determining the impact of aerosols on surface precipitation from clouds: An attempt at classification, J. Atmos. Sci., 65, 1721-1748, 2008.

Köhler, H.: The nucleus in the growth of hygroscopic droplets, T. Faraday Soc., 32, 1152-1161, 1936.

Kumar, P., Sokolik, I. N., and Nenes, A.: Parameterization of cloud droplet formation for global and regional models: including ad- 
sorption activation from insoluble CCN, Atmos. Chem. Phys., 9, 2517-2532, doi:10.5194/acp-9-2517-2009, 2009.

Lance, S., Shupe, M. D., Feingold, G., Brock, C. A., Cozic, J., Holloway, J. S., Moore, R. H., Nenes, A., Schwarz, J. P., Spackman, J. R., Froyd, K. D., Murphy, D. M., Brioude, J., Cooper, O. R., Stohl, A., and Burkhart, J. F.: Cloud condensation nuclei as a modulator of ice processes in Arctic mixed-phase clouds, Atmos. Chem. Phys., 11, 8003-8015, doi:10.5194/acp-11-80032011, 2011.

Leaitch, W. R., Isaac, G. A., Strapp, J. W., Banic, C. M., and Wiebe, H. A.: The relationship between cloud droplet number concentrations and anthropogenic pollution: Observations and climatic implications, J. Geophys. Res., 97, 2463-2474, doi:10.1029/91JD02739, 1992.

Levy, R. C., Mattoo, S., Munchak, L. A., Remer, L. A., Sayer, A. M., Patadia, F., and Hsu, N. C.: The Collection 6 MODIS aerosol products over land and ocean, Atmos. Meas. Tech., 6, 29893034, doi:10.5194/amt-6-2989-2013, 2013.

Liu, X., Xie, S., Boyle, J., Klein, S. A., Shi, X., Wang, Z., Lin, W., Ghan, S. J., Earle, M., Liu, P. S. K., and Zelenyuk, A.: Testing cloud microphysics parameterizations in NCAR CAM5 with ISDAC and M-PACE observations, J. Geophys. Res., 116, D00T11, doi:10.1029/2011JD015889, 2011.

Liu, X., Easter, R. C., Ghan, S. J., Zaveri, R., Rasch, P., Shi, X., Lamarque, J.-F., Gettelman, A., Morrison, H., Vitt, F., Conley, A., Park, S., Neale, R., Hannay, C., Ekman, A. M. L., Hess, P., Mahowald, N., Collins, W., Iacono, M. J., Bretherton, C. S., Flanner, M. G., and Mitchell, D.: Toward a minimal representation of aerosols in climate models: description and evaluation in the Community Atmosphere Model CAM5, Geosci. Model Dev., 5, 709-739, doi:10.5194/gmd-5-709-2012, 2012.

Mårtensson, E., Nilsson, E., de Leeuw, G., Cohen, L., and Hansson, H.-C.: Laboratory simulations and parameterisation of the primary marine aerosol production, J. Geophys. Res., 108, 4297, doi:10.1029/2002JD002263, 2003.

Martin, G. M., Johnson, D. W., and Spice, A.: The measurement and parameterization of effective radius of droplets in warm stratocumulus clouds, J. Atmos. Sci., 51, 1823-1842, 1994.

Merikanto, J., Napari, I., Vehkamaki, H., Anttila, T., and Kulmala, M.: New parameterization of sulfuric acid-ammonia-water ternary nucleation rates at tropospheric conditions, J. Geophys. Res., 112, D15207, doi:10.1029/2006JD007977, 2007.

Monahan, E., Spiel, D., and Davidson, K.: A model of marine aerosol generation via white caps and wave disruption, in: Oceanic whitecaps, edited by: Monahan, E. and MacNiochaill, G., 167-193, Dordrecht, Reidel, The Netherlands, 1986.

Moore, R. H., Karydis, V. A., Capps, S. L., Lathem, T. L., and Nenes, A.: Droplet number uncertainties associated with $\mathrm{CCN}$ : an assessment using observations and a global model adjoint, Atmos. Chem. Phys., 13, 4235-4251, doi:10.5194/acp-13-42352013, 2013.

Morales Betancourt, R. and Nenes, A.: Droplet activation parameterization: the population splitting concept revisited, Geosci. Model Dev. Discuss., 7, 2903-2932, doi:10.5194/gmdd-7-29032014, 2014.

Morrison, H. and Gettelman, A.: A new two-moment bulk stratiform cloud microphysics scheme in the Community Atmosphere Model, Version 3 (CAM3), part I: description and numerical tests, J. Climate, 21, 3642-3659, doi:10.1175/2008JCLI2105.1, 2008.

Nenes, A. and Seinfeld, J. H.: Parameterization of cloud droplet formation in global climate models, J. Geophys. Res., 108, 4415, doi:10.1029/2002JD002911, 2003.

Nenes, A., Ghan, S., Abdul-Razzak, H., Chuang, P. Y., and Seinfeld, J. H.: Kinetic limitations on cloud droplet formation and impact on cloud albedo, Tellus B, 53, 133-149, doi:10.1034/j.16000889.2001.d01-12.x, 2001.

Ovtchinnikov, M. and Ghan, S. J.: Parallel simulations of aerosol influence on clouds using cloud-resolving and single-column models, J. Geophys. Res., 110, D15S10, doi:10.1029/2004JD005088, 2005.

Petters, M. D. and Kreidenweis, S. M.: A single parameter representation of hygroscopic growth and cloud condensation nucleus activity, Atmos. Chem. Phys., 7, 1961-1971, doi:10.5194/acp-71961-2007, 2007.

Platnick, S. and S. Twomey: Determining the susceptibility of cloud albedo to changes in droplet concentration with the advanced very high resolution radiometer, J. Appl. Meteorol., 33, 334-347, doi:10.1175/15200450(1994)033<0334:DTSOCA>2.0.CO;2, 1994.

Ramanathan, V., Crutzen, P. J., Kiehl, J. T., and Rosenfeld, D.: Aerosols, Climate, and The Hydrological Cycle, Science, 294, 2119-2124, doi:10.1126/science.1064034, 2001.

Rosenfeld, D., Lohmann, U., Raga, G. B., O’Dowd, C. D., Kulmala, M., Fuzzi, S., Reissell, A., and Andreae, M. O., Flood or drought: How do aerosols affect precipitation?, Science, 321, 1309-1313, 2008.

Reutter, P., Su, H., Trentmann, J., Simmel, M., Rose, D., Gunthe, S. S., Wernli, H., Andreae, M. O., and Pöschl, U.: Aerosol- and updraft-limited regimes of cloud droplet formation: influence of particle number, size and hygroscopicity on the activation of cloud condensation nuclei (CCN), Atmos. Chem. Phys., 9, 70677080, doi:10.5194/acp-9-7067-2009, 2009.

Song, X., Zhang, G. J., and Li J.-L. F.: Evaluation of microphysics parameterization for convective clouds in the NCAR Community Atmosphere Model CAM5, J. Clim., 25, 8568-8590, 2012.

Twomey, S.: Pollution and the planetary albedo, Atmos. Environ., 8, 1251-1256, doi:10.1016/0004-6981(74)90004-3, 1974.

Twomey, S.: Influence of pollution on shortwave albedo of clouds, J. Atmos. Sci., 34, 1149-1152, doi:10.1175/15200469(1977)034,1149:TIOPOT.2.0.CO;2, 1977.

Twomey, S.: Aerosols, clouds and radiation, Atmos. Environ., 25A, 2435-2442, doi:10.1016/0960-1686(91)90159-5, 1991.

Vehkamäki, H., Kulmala, M., Napari, I., Lehtinen, K. E. J., Timmreck, C., Noppel, M., and Laaksonen, A.: An improved parameterization for sulfuric acid water nucleation rates for tropospheric and stratospheric conditions, J. Geophys. Res., 107, 4622-4632, doi:10.1029/2002JD002184, 2002.

Wang, M., Penner, J. E., and Liu, X.: Coupled IMPACT aerosol and NCAR CAM3 model: Evaluation of predicted aerosol number and size distribution, J. Geophys. Res., 114, D06302, doi:10.1029/2008JD010459, 2009.

Xie, S., Liu, X., Zhao, C., and Zhang, Y.: Sensitivity of CAM5simulated arctic clouds and radiation to ice nucleation parameterization, J. Climate, 26, 5981-5999, doi:10.1175/JCLI-D-1200517.1, 2013. 
Yang, B., Qian, Y., Lin, G., Leung, L-Y, Rasch, P. J., Zhang, G. J., McFarlane, S. A., Zhao, C., Zhang, Y., Wang, H., Wang, M., and Liu, X.: Uncertainty quantification and parameter tuning in the CAM5 Zhang-McFarlane convection scheme and impact of improved convection on the global circulation and climate, J. Geophys. Res. Atmos., 118, 395-415, doi:10.1029/2012JD018213, 2013.

Yu, F.: Ion-mediated nucleation in the atmosphere: Key controlling parameters, implications, and look-up table, J. Geophys. Res., 115, D03206, doi:10.1029/2009JD012630, 2010.

Zender, C., Bian, H., and Newman, D.: Mineral Dust Entrainmentand Deposition (DEAD) model: Description and 1990s dust climatology, J. Geophys. Res., 108, 4416-4437, doi:10.1029/2002JD002775, 2003.
Zhang, G. J. and McFarlane, N. A.: Sensitivity of climate simulations to the parameterization of cumulus convection in the Canadian Climate Centre general circulation model, Atmos. Ocean, 33, 407-446, 1995.

Zhang, Y.: Online-coupled meteorology and chemistry models: history, current status, and outlook, Atmos. Chem. Phys., 8, 28952932, doi:10.5194/acp-8-2895-2008, 2008.

Zhang, Y., Karamchandani, P., Glotfelty, T., Streets, D. G., Skamarock, W. C., Grell, G., Nenes, A., Yu, F., and Bennartz, R.: Development and initial application of the GlobalThrough-Urban Weather Research and Forecasting Model with Chemistry (GU-WRF/Chem), J. Geophys. Res., 117, D20206, doi:10.1029/2012JD017966, 2012. 